\title{
Comprehensive review of visual defects reported with topiramate
}

This article was published in the following Dove Press journal:

Clinical Ophthalmology

23 May 2017

Number of times this article has been viewed

\author{
Lisa Ford' \\ Jeffrey L Goldberg ${ }^{2}$ \\ Fred Selan' \\ Howard E Greenberg' \\ Yingqi Shi' \\ 'Janssen Research \& Development, \\ LLC, Titusville, NJ, ' ${ }^{2}$ Byers Eye \\ Institute, Stanford University, \\ Palo Alto, CA, USA
}

Correspondence: Lisa Ford Neurosciences, Janssen Research \& Development, LLC, II 25 TrentonHarbourton Road, Titusville, NJ 08560, USA

Tel +l 6097302909

Fax +I 6097304583

Email IfordI@its.jnj.com
Objective: The objective of this study was to analyze clinical patterns of visual field defects (VFDs) reported with topiramate treatment and assess possible mechanism of action (MOA) for antiepileptic drug (AED) associated VFDs.

Methods: A comprehensive topiramate database review included preclinical data, sponsor's clinical trials database, postmarketing spontaneous reports, and medical literature. All treatmentemergent adverse events (TEAEs) suggestive of retinal dysfunction/damage were summarized. Relative risk (RR) was computed from topiramate double-blind, placebo-controlled trials (DBPCTs) data.

Results: Preclinical studies and medical literature review suggested that despite sharing gamma-aminobutyric acid (GABA)-ergic MOA with other AEDs, topiramate treatment was not associated with VFDs. TEAEs suggestive of retinal dysfunction/damage were observed in $0.3 \%-0.7 \%$ of adults and pediatric patients with topiramate $(\mathrm{N}=4,679)$ versus $\leq 0.1 \%$ with placebo $(\mathrm{N}=1,834)$ in DBPCTs for approved indications (epilepsy and migraine prophylaxis); open-label trials (OLTs) and DBPCTs for investigational indications had similar incidence. Overall, $88 \%$ TEAEs were mild or moderate in severity. Serious TEAEs were very rare (DBPCTs: 0\%; OLTs: $\leq 0.1 \%$ ), and most were not treatment limiting, and resolved. The most common visual TEAEs (approved indications) were VFD, scotoma, and optic atrophy. The incidence of TEAEs in DBPCTs (approved and investigational indications) was higher in topiramate-treated $(\mathrm{N}=9,169)$ versus placebo-treated patients $(\mathrm{N}=5,023 ; 0.36 \%$ vs $0.24 \%)$, but the RR versus placebo-treated patients was not significant (RR: 1.51 [95\% confidence interval: $0.78,2.91])$.

Conclusion: VFDs do not appear to be a class effect for AEDs with GABA-ergic MOA. The RR for VFDs is not significantly different between topiramate and placebo treatment.

Keywords: gamma-aminobutyric acid, retinal dysfunction, scotoma, topiramate, visual field defects

\section{Introduction}

Globally, topiramate is approved in children and adults for at least one indication including adjunctive and monotherapy treatment of partial onset seizures and primary generalized tonic-clonic seizures as well as adjunctive treatment of seizures associated with Lennox-Gastaut syndrome, and in adolescents and adults for migraine prophylaxis. $^{1}$

The precise mechanisms by which topiramate, a sulfamate-substituted monosaccharide, exerts its antiseizure and migraine prophylactic effects are unknown. Results from electrophysiological and biochemical studies on cultured neurons have suggested three properties that may contribute to the antiepileptic efficacy of topiramate: sodium channel blocking action, potentiation of the inhibitory 
neurotransmitter gamma-aminobutyric acid (GABA), and antagonism of the kainate/ $\alpha$-amino-3-hydroxy-5methylisoxazole-4-propionic acid (AMPA) subtype of the excitatory amino acid glutamate receptor. ${ }^{2}$ GABA is a more potent modulator in the retina and GABA potentiation is the mechanism of action (MOA) of several antiepileptic drugs (AEDs) including vigabatrin and pregabalin. ${ }^{3-6}$

Visual field defects (VFDs) can manifest as scotoma, both homonymous and heteronymous hemianopia, and peripheral vision loss or tunnel vision. ${ }^{7}$ A variety of ophthalmologic treatment-emergent adverse events (TEAEs) have been reported with topiramate use, including acute angle-closure glaucoma, maculopathy, ciliochoroidal detachment, ciliary body edema, and acute myopic shift, some of which are associated with VFDs. ${ }^{1,8-10}$ These TEAEs suggest that topiramate therapy has the potential to cause VFDs. Preclinical findings in topiramate-treated rabbits suggest that topiramate may damage the retina, similar to vigabatrin. ${ }^{11}$ In humans, $\sim 30 \%$ of adult patients exposed to vigabatrin have reported some degree of VFDs that are irreversible. ${ }^{12,13}$ This study was aimed to determine the possible MOA for VFDs reported with topiramate treatment and to comprehensively analyze clinical patterns including type of VFDs, risk factors for their development, relationship to topiramate dose and duration of therapy, and persistence of VFDs.

\section{Methods}

\section{Literature search}

A search and review of the cases from the global safety database (SCEPTRE) was carried out for only spontaneous cases. No formal literature review was conducted and reviewed in this report. However, cases reported from the literature may have been included in the SCEPTRE if the Center of Excellence identified the published literature in their searches.

Valid, spontaneous, medically confirmed or not confirmed cases with topiramate as suspect or suspect-interacting drug (highest version in date range) received cumulatively through May 31, 2013, were included in the review. Cases that were in workflow at the time of the database search were not captured as part of this search. Also, adverse events were coded to the preferred terms (PTs) included in the Medical Dictionary for Regulatory Activities (MedDRA, version 16.0).

All cases were retrieved independent of the reporter's relationship attribution, and all spontaneous cases were considered possibly related at the time of entry into the database. Therefore, individual assessments may not be in agreement with the causality assessment of the reporter.

\section{Comparison with other GABA-ergic medications}

Pregabalin and vigabatrin have a GABA-ergic MOA and are associated with VFDs. Topiramate has a similar MOA. Thus, the MOA of topiramate, pregabalin, and vigabatrin, and its association with VFDs were reviewed based on a search of the medical literature. Differences in how these three drugs inhibit GABA signaling may still account for differences in their adverse event profiles. VFDs were defined as TEAEs coded to PTs included in MedDRA (version 14.0) high level term visual field disorders (Table S1).

Concern about a possible association of topiramate therapy with VFDs and its possible relationship to a significant reduction of retinal function appears to arise, at least partly, from a study by Kjellström et al. ${ }^{11}$ Other studies have further examined the effects of vigabatrin, pregabalin, and topiramate on cerebral and retinal GABA levels in animal models. A formal literature search was conducted to identify animal studies.

Preclinical evidence that explored topiramate's effects on visual function was summarized from animal studies, including topiramate's effects on retinal function and histopathology in rabbits; ${ }^{11}$ effects of gabapentin, vigabatrin, and topiramate in rats, ${ }^{5}$ topiramate in an excitotoxin-induced neurotoxicity model that used two different retinal primary cultures, and a rat model of retinal ischemic injury. ${ }^{14}$ A clinical study (healthy volunteers) assessing the effect of topiramate, lamotrigine, and gabapentin on cerebral GABA levels was also reviewed. ${ }^{3}$

A comprehensive retrospective data review included analysis of all Janssen R\&D sponsored data from doubleblind, placebo-controlled trials (DBPCTs) and open-label trials (OLTs) in approved and investigational indications for topiramate, and postmarketing spontaneous reports (Janssen R\&D safety database). In addition, the medical literature for AEDs (cutoff date: April 2015) was reviewed.

\section{Comprehensive retrospective review of clinical trial data}

All Janssen R\&D-sponsored trials for topiramate in approved and investigational indications reviewed for this analysis were approved indications: adjunctive treatment of epilepsy (DBPCTs $=17$, OLTs $=30$ ), monotherapy treatment of epilepsy (DBPCTs $=5$, OLTs $=3$ ), and migraine prophylaxis (DBPCTs $=13$, OLTs $=8$ ); investigational indications: bipolar disorder (DBPCTs $=7$, OLTs $=5$ ), essential tremor $(\mathrm{DBPCTs}=1, \mathrm{OLTs}=1)$, binge eating disorder $(\mathrm{DBPCTs}=2$, OLTs $=1$ ), diabetic peripheral neuropathy $($ DBPCTs $=5$, 
OLTs $=4$ ), obesity (DBPCTs $=11$, OLTs $=1$ ), alcohol dependency (DBPCTs =1), and cognitive function (observerblinded trial $=1$ ).

\section{Spontaneous postmarketing reports from Janssen R\&D safety database}

All spontaneously reported postmarketing cases (July 1995 to April 2015) of visual symptoms possibly associated with retinal dysfunction were reviewed in topiramate-treated patients. The Global Medical Safety database, Strategic Clinical and Epidemiological Pharmacovigilance Technology for Risk Evaluation were searched for all medically confirmed and consumer reported cases, using prespecified MedDRA high level terms or system-organ class or both.

\section{Data analysis}

The search terms used for TEAEs suggestive of retinal dysfunction or damage were PTs coded using MedDRA (version 14.0). For DBPCTs, TEAEs were summarized for each indication separately and for all doses combined (for patients randomized to topiramate and placebo, but not to active controls). For studies with only flexible doses of topiramate and without fixed dose groups, all topiramate-treated patients were combined in one group and the actual administered dose range was indicated. All randomized patients who took at least one dose of topiramate or placebo were included in the summaries. For OLTs, TEAEs were summarized for all topiramate-treated patients by indication, combining all doses. Patients randomized to an active comparator medication during the double-blind (DB) phase, but who were switched to topiramate during the open-label (OL) phase, were added to the topiramate group. Relative risk (RR) was calculated for the DBPCTs using a derived dataset which included, from each study, the number of patients on topiramate and placebo, and the number of patients with retinal-related TEAEs per treatment group. All spontaneously reported postmarketing cases that included topiramate, identified as either a suspect including co-suspect, suspect-interacting, or concomitant medication were retrieved, independent of the reporter's relationship attribution. There were too few patients per dose category to allow for stratification by dose analysis.

Studies were combined by treatment group (topiramate or placebo). The proportions and RR were then calculated based on a $2 \times 2$ table that resulted from the pooled dataset. The $P$-value was calculated based on a chi-square test. RR, its standard error, and 95\% confidence interval were calculated according to Altman. ${ }^{15}$

\section{Results \\ Relationship of GABA-ergic MOA to VFDs}

Human studies

Topiramate, vigabatrin, and pregabalin share a GABAergic component in their MOA. Furthermore, other drugs (barbiturates, benzodiazepines, and tiagabine) with a GABAergic component in their MOA do not affect retinal function in humans. ${ }^{16-18}$ Cerebral GABA levels were elevated in healthy adults treated with topiramate, lamotrigine, or gabapentin; however, no correlation with VFDs was observed. ${ }^{5}$

\section{Animal studies}

Retinal immunohistology revealed significant accumulation of GABA in amacrine cells in the inner nuclear layer and in the inner plexiform layer in 4 of 6 topiramate-treated rabbits, compared with controls. ${ }^{11}$ However, serum topiramate levels in these rabbits $(6.4-15.8 \mu \mathrm{mol} / \mathrm{L})$ were comparatively lower than in patients with refractory focal epilepsy (6-56 $\mu \mathrm{mol} / \mathrm{L})$, who did not demonstrate any dose-related VFDs $;{ }^{19}$ results seemed to be affected by the poor tolerability of topiramate in rabbits.

In rats $(\mathrm{N}=110)$ treated with vigabatrin, topiramate, or gabapentin, retinal GABA concentrations were significantly increased with vigabatrin, but not with topiramate or gabapentin treatment; ${ }^{5}$ results suggesting important differences among these drugs on retinal GABA metabolism. Topiramate decreased the excitotoxin-induced neurotoxicity of glutamate or AMPA in a concentration-dependent manner in retinal or retinal ganglion cell cultures. ${ }^{14}$ In a rat model, topiramate reduced the ischemia-induced decrease in the amplitude of the electroretinogram b-waves 3 days after ischemia and ischemia-induced retinal degenerative changes.

These data from both human and animal studies suggest that retinal toxicity is not a class-specific TEAE in GABAergic AEDs, but rather significant variation exists within this class. Overall, this review of AEDs associated with VFDs suggested that VFDs were not a class effect for drugs having a GABA-ergic component in their MOA.

\section{Comprehensive retrospective review of clinical trial data}

Trials in approved indications

Across these trials, topiramate DB exposure for patients was up to 16 weeks, and OL phase median exposure was approximately 1 year. 
DBPCTs (NCT0023 I556; NCT00236639; NCT0023 I530; NCT00236730; NCT0023669I)

The incidence of TEAEs suggestive of retinal dysfunction or damage was higher among topiramate-treated patients ( $\mathrm{N}=4,679$; ranging from $0.3 \%$ to $0.7 \%$ for all topiramate doses combined) compared with placebo-treated patients $(\mathrm{N}=1,834 ; \leq 0.1 \%$, retinal tear in one patient in the migraine prophylaxis indication) (Table 1). The most commonly reported TEAEs among topiramate-treated patients were VFDs $(0.3 \%$ in each indication) and scotoma $(<0.1 \%$ to $0.4 \%$ across indications); TEAEs occurred in the dose range, $50-1,000 \mathrm{mg} /$ day. All events were mild or moderate in severity with no serious TEAEs. Treatment limiting VFDs occurred in 2 patients (migraine prophylaxis indication), which led to permanent discontinuation of the study drug in 1 patient, and dose reduction in the other (VFDs resolved in both).

\section{OLTs}

The incidence of TEAEs suggestive of retinal dysfunction or damage ranged from $0.3 \%(7 / 2,750)$ in migraine studies to $0.7 \%$ in monotherapy epilepsy studies (all topiramate doses combined) (Table 1). For migraine studies, this included patients who received placebo during the DB phase, but who switched to topiramate in the OL phase. The majority of TEAEs reported in topiramate-treated patients were VFDs (all indications: $0.1 \%-0.4 \%$ ), scotoma (migraine prophylaxis and monotherapy epilepsy: $<0.1 \%$ to $0.4 \%$ ), and optic atrophy (adjunctive epilepsy: $0.2 \%$ ). Optic atrophy TEAEs were all reported for patients receiving adjunctive topiramate treatment for epilepsy, who were also concomitantly receiving valproate, another AED that has been associated with VFDs. ${ }^{18,20,21}$ Most of the TEAEs were mild or moderate in severity; the majority resolved. Few TEAEs were serious: retinal hemorrhage in 1 patient in monotherapy epilepsy indication (resolved) and occlusion of retinal vein in 1 patient in migraine prophylaxis indication (persisted). In topiramate-treated patients, the study drug was discontinued in 4 patients (VFD, tunnel vision, retinal hemorrhage, and occlusion of retinal vein, $\mathrm{N}=1$ in each; all 3 events except retinal vein occlusion resolved), and dose was adjusted in 1 patient (optic atrophy).

\section{Trials in investigational indications}

\section{DBPCTs}

The incidence of TEAEs suggestive of retinal dysfunction or damage ranged from $0 \%$ to $0.8 \%$ among topiramate-treated patients, compared with $0 \%-1.1 \%$ among placebo-treated
Table I TEAEs suggestive of retinal damage reported in approved indication studies

\begin{tabular}{|c|c|c|}
\hline & $\begin{array}{l}\text { Placebo } \\
\mathbf{N}(\%)\end{array}$ & $\begin{array}{l}\text { All TPM } \\
\mathbf{N}(\%)\end{array}$ \\
\hline \multicolumn{3}{|l|}{ Adjunctive epilepsy trials } \\
\hline DB phase: $100-400,600-1,000$ mg/day, & $(\mathrm{N}=570)$ & $(\mathrm{N}=1,099)$ \\
\hline \multicolumn{3}{|l|}{$5-25 \mathrm{mg} / \mathrm{kg} / \mathrm{day}$} \\
\hline Patients with retinal damage TEAEs & 0 & $5(0.5)$ \\
\hline Scotoma & 0 & $\mathrm{I}(0.1)$ \\
\hline Tunnel vision & 0 & $\mathrm{I}(0 . \mathrm{I})$ \\
\hline VFD & 0 & $3(0.3)$ \\
\hline OL phase & $(\mathrm{N}=264)^{\mathrm{a}}$ & $(\mathrm{N}=2,262)^{\mathrm{a}}$ \\
\hline Patients with retinal damage TEAEs & 0 & $12(0.5)$ \\
\hline Blindness & 0 & $I(<0.1)$ \\
\hline Optic atrophy & 0 & $4(0.2)$ \\
\hline Papillophlebitis & 0 & $\mathrm{I}(<0.1)$ \\
\hline Retinal hemorrhage & 0 & $\mathrm{I}(<0.1)$ \\
\hline Retinal vein occlusion & 0 & $\mathrm{I}(<0 . \mathrm{I})$ \\
\hline VFD & 0 & $4(0.2)$ \\
\hline \multicolumn{3}{|l|}{ Monotherapy epilepsy trials } \\
\hline DB phase: $50,100,200,400$ & - & $(\mathrm{N}=\mathrm{I}, 365)$ \\
\hline \multicolumn{3}{|l|}{$500 \mathrm{mg} /$ day } \\
\hline Patients with retinal damage TEAEs & & $10(0.7)$ \\
\hline Retinal hemorrhage & & $I(0.1)$ \\
\hline Scotoma & & $5(0.4)$ \\
\hline VFD & & $4(0.3)$ \\
\hline OL phase & - & $(\mathrm{N}=708)^{\mathrm{b}}$ \\
\hline Patients with retinal damage TEAEs & & $5(0.7)$ \\
\hline Blindness & & $\mathrm{I}(0.1)$ \\
\hline Macular degeneration & & $\mathrm{I}(0.1)$ \\
\hline Retinal hemorrhage & & $\mathrm{I}(0.1)^{\mathrm{d}}$ \\
\hline Scotoma & & $3(0.4)$ \\
\hline VFD & & $\mathrm{I}(0.1)$ \\
\hline \multicolumn{3}{|l|}{ Migraine prophylaxis trials } \\
\hline DB phase: $50,100,200 \mathrm{mg} /$ day, & $(\mathrm{N}=\mathrm{I}, 264)$ & $(\mathrm{N}=2,215)$ \\
\hline \multicolumn{3}{|l|}{$2-3 \mathrm{mg} / \mathrm{kg} / \mathrm{day}$} \\
\hline Patients with retinal damage TEAEs & $\mathrm{I}(0 . \mathrm{I})$ & $7(0.3)$ \\
\hline Retinal tear & $\mathrm{I}(0.1)$ & 0 \\
\hline Scotoma & 0 & $\mathrm{I}(<0.1)$ \\
\hline VFD & 0 & $6(0.3)$ \\
\hline OL phase & $(\mathrm{N}=492)^{\mathrm{c}}$ & $(\mathrm{N}=2,258)^{\mathrm{c}}$ \\
\hline Patients with retinal damage TEAEs & $2(0.4)$ & $5(0.2)$ \\
\hline Blindness & 0 & $\mathrm{I}(<0 . \mathrm{I})$ \\
\hline Retinal degeneration & 0 & $I(<0.1)$ \\
\hline Retinal vein occlusion & 0 & $\mathrm{I}(<0.1)^{\mathrm{d}}$ \\
\hline Scotoma & 0 & $\mathrm{I}(<0.1)$ \\
\hline Tunnel vision & 0 & $\mathrm{I}(<0 . \mathrm{I})$ \\
\hline VFD & $2(0.4)$ & 0 \\
\hline
\end{tabular}

Notes: aPlacebo group: patients who received placebo in DB phase but were switched to TPM during OL phase. TPM group: patients who received TPM during the DB phase and $\mathrm{OL}$ phase. ${ }^{\mathrm{b}} \mathrm{All}$ patients received TPM during the OL phase. TPM: patients who were randomized to an active control during DB phase. 'Placebo group: patients who received placebo in DB phase but were switched to TPM during OL phase. TPM group: patients who received TPM or an active comparator during the DB phase and who either remained on TPM or were switched from active control to TPM during the $\mathrm{OL}$ phase. ¿Serious TEAEs.

Abbreviations: DB, double-blind; OL, open-label; TEAE, treatment-emergent adverse event; TPM, topiramate; VFD, visual field defect.

patients (Table 2). This is based on TEAEs suggestive of retinal damage reported in investigational indication studies. The most commonly reported TEAE was VFD $(0.1 \%-0.5 \%$ in all indications; none serious). These events 
Table 2 TEAEs suggestive of retinal damage reported in investigational indication studies

\begin{tabular}{|c|c|c|}
\hline & $\begin{array}{l}\text { Placebo } \\
\text { N (\%) }\end{array}$ & $\begin{array}{l}\text { All TPM } \\
\mathbf{N}(\%)\end{array}$ \\
\hline \multicolumn{3}{|l|}{ Bipolar disorder } \\
\hline DB phase: $\leq 200,>200-400$ & $(\mathrm{~N}=630)$ & $(\mathrm{N}=892)$ \\
\hline \multicolumn{3}{|l|}{$500-600 \mathrm{mg} /$ day } \\
\hline Patients with retinal damage TEAEs & 0 & $2(0.2)$ \\
\hline Retinal degeneration & 0 & $\mathrm{I}(0.1)$ \\
\hline VFD & 0 & $\mathrm{I}(0.1)$ \\
\hline OL phase & $(\mathrm{N}=26 \mathrm{I})^{\mathrm{a}}$ & $(\mathrm{N}=436)^{\mathrm{a}}$ \\
\hline Patients with retinal damage TEAEs & 0 & $\mathrm{I}(0.2)$ \\
\hline Vitreous hemorrhage & 0 & $\mathrm{I}(0.2)$ \\
\hline \multicolumn{3}{|l|}{ Binge eating disorder } \\
\hline DB phase: $200,400 \mathrm{mg} / \mathrm{day}$ & $(\mathrm{N}=202)$ & $\begin{array}{l}\text { TPM } 400 \mathrm{mg} / \text { day } \\
(\mathrm{N}=202)\end{array}$ \\
\hline Patients with retinal damage TEAEs & 0 & $\mathrm{I}(0.5)$ \\
\hline VFDs & 0 & $\mathrm{I}(0.5)$ \\
\hline \multicolumn{3}{|l|}{ Diabetic peripheral neuropathy } \\
\hline DB phase: $100,200,400 \mathrm{mg} /$ day & $(\mathrm{N}=53 \mathrm{I})$ & $(\mathrm{N}=\mathrm{I}, \mid \mathrm{40})$ \\
\hline Patients with retinal damage TEAEs & $6(1.1)$ & $9(0.8)$ \\
\hline Optic atrophy & $\mathrm{I}(0.2)$ & 0 \\
\hline Optic nerve disorder & 0 & $\mathrm{I}(0.1)$ \\
\hline Retinal detachment & $2(0.4)$ & 0 \\
\hline Retinal hemorrhage & $2(0.4)$ & $\mathrm{I}(0.1)$ \\
\hline Retinal infarction & 0 & $\mathrm{I}(0.1)$ \\
\hline Retinal tear & 0 & $\mathrm{I}(0.1)$ \\
\hline Retinopathy & 0 & $2(0.2)$ \\
\hline Scotoma & 0 & $\mathrm{I}(0.1)$ \\
\hline Vitreous adhesions & 0 & $\mathrm{I}(0.1)$ \\
\hline Vitreous hemorrhage & $2(0.4)$ & 0 \\
\hline VFD & 0 & $\mathrm{I}(0 . \mathrm{I})$ \\
\hline OL phase & $(\mathrm{N}=357)^{\mathrm{b}}$ & $(\mathrm{N}=574)^{\mathrm{b}}$ \\
\hline Patients with retinal damage TEAEs & $6(1.7)$ & $7(1.2)$ \\
\hline Macular edema & $\mathrm{I}(0.3)$ & 0 \\
\hline Retinal detachment & $\mathrm{I}(0.3)$ & $\mathrm{I}(0.2)^{\mathrm{c}}$ \\
\hline Retinal hemorrhage & $2(0.6)$ & $\mathrm{I}(0.2)$ \\
\hline Retinopathy & $2(0.6)$ & $4(0.7)$ \\
\hline Tunnel vision & 0 & $\mathrm{I}(0.2)$ \\
\hline \multicolumn{3}{|l|}{ Obesity } \\
\hline DB phase: $<100,100-200$ & $(\mathrm{~N}=1,373)$ & $(\mathrm{N}=3,164)$ \\
\hline \multicolumn{3}{|l|}{$>200-400 \mathrm{mg} /$ day } \\
\hline Patients with retinal damage TEAEs & $5(0.4)$ & $9(0.3)$ \\
\hline Macular degeneration & $\mathrm{I}(0.1)$ & 0 \\
\hline Retinal disorder & $\mathrm{I}(0.1)$ & 0 \\
\hline Retinal hemorrhage & $\mathrm{I}(0.1)$ & $\mathrm{I}(<0 . \mathrm{I})$ \\
\hline Scotoma & 0 & $\mathrm{I}(<0 . \mathrm{I})$ \\
\hline Tunnel vision & 0 & $3(0.1)$ \\
\hline VFD & $2(0.1)$ & $4(0.1)$ \\
\hline
\end{tabular}

Notes: aPlacebo group: patients who received placebo in DB phase but were switched to TPM during OL phase. TPM group: patients who received TPM or an active comparator during the DB phase and who either remained on TPM or were switched from active control to TPM during the OL phase. 'Placebo group: patients who received placebo in DB phase but were switched to TPM during the OL phase. TPM group: patients who received TPM during the DB phase and OL phase. 'Serious TEAE.

Abbreviations: DB, double-blind; OL, open-label; TEAE, treatment-emergent adverse event; TPM, topiramate; VFDs, visual field defects.

occurred in patients treated with topiramate in a dose range of $<100-600 \mathrm{mg} /$ day. Three events from studies conducted for an obesity indication were treatment limiting: two patients discontinued the study drug (tunnel vision, events resolved) while one patient had a dose reduction (retinal hemorrhage). In the placebo-treated patients, the most frequent adverse event was retinal hemorrhage.

\section{OLTs}

The incidence of TEAEs suggestive of retinal dysfunction or damage in the OLTs was $<0.1 \%$ except for the diabetic peripheral neuropathy indication (1.4\%) (Table 2). The most commonly reported events among topiramate-treated patients (including those receiving placebo during the DB phase who switched to topiramate during $\mathrm{OL})$ were retinopathy $(0.6 \%)$, retinal hemorrhage $(0.3 \%)$, and retinal detachment $(0.2 \%)$, all in the diabetic neuropathy indication. Only one serious event of retinal detachment (diabetic neuropathy indication) was reported. One TEAE that was treatment limiting (retinal detachment) resolved after the study drug was temporarily discontinued.

\section{RR analysis}

Only DBPCTs in both approved and investigational indications were included in the RR analysis, for which all topiramate dose groups and events were combined due to sparse data. The incidence of events in the topiramate group $(0.36 \%)$ was not significantly different from that in the placebo group ( $0.24 \%$; RR of topiramate vs placebo treatment $1.51 ; 95 \%$ confidence interval: $0.78,2.91$ ) (Figure 1).

\section{Spontaneous postmarketing reports}

From July 1995 to April 2015, 96 spontaneous postmarketing reports of visual field disorders in topiramate-treated patients were retrieved, which included VFDs ( $\mathrm{N}=89)$, tunnel vision $(\mathrm{N}=11)$, scotoma $(\mathrm{N}=6)$, hemianopia homonymous $(\mathrm{N}=4)$, and hemianopia $(\mathrm{N}=3)$. The largest number of cases occurred in the 36-50 age group and women. VFDs were considered

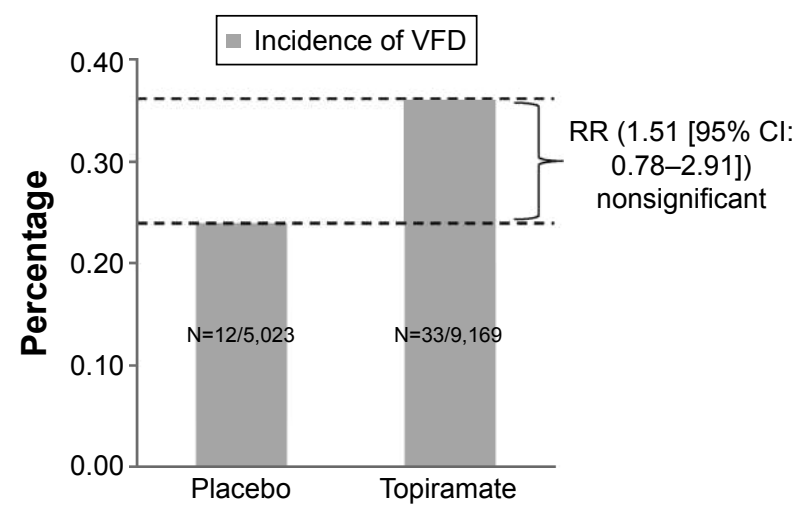

Figure I Risk analysis for VFDs.

Notes: RR for VFDs between the topiramate group (all dose groups combined) and placebo group was not significant. $95 \% \mathrm{Cl}(0.78,2.91)$.

Abbreviations: $\mathrm{Cl}$, confidence interval; $\mathrm{RR}$, relative risk; VFDs, visual field defects. 
serious in $68 \%$ of the overall cases (Table 3 ). The latency of the cases was variable, ranging from a few hours up to 10 years. Of the 96 case reports, 75 were excluded by caselevel review, because of poor documentation $(\mathrm{N}=42)$, not confirmed medically $(\mathrm{N}=15)$, or confounded by concomitant disease or medication $(\mathrm{N}=18)$. The remaining 21 reports included 14 cases that were confirmed medically and 7 cases that were not. Of the 14 medically confirmed cases, 13 cases ( 2 were duplicates, hence only one was retained) reported a plausible temporal relationship between exposure to the drug

Table 3 Patient demographics, seriousness, latency, and reversibility for patients of VFD reported with topiramate treatment

\begin{tabular}{|c|c|}
\hline Characteristics & $\begin{array}{l}\text { Number of patients } \\
N=96\end{array}$ \\
\hline \multicolumn{2}{|l|}{ Sex } \\
\hline Men & 25 \\
\hline Women & 66 \\
\hline Not reported & 5 \\
\hline \multicolumn{2}{|l|}{ Age group (years) } \\
\hline$\leq 17$ & 8 \\
\hline $18-35$ & 26 \\
\hline $36-50$ & 30 \\
\hline $5 I-64$ & 13 \\
\hline$\geq 65$ & 5 \\
\hline Not reported & 14 \\
\hline \multicolumn{2}{|l|}{ Indication ( $\geq 2$ patients) } \\
\hline Epilepsy & 24 \\
\hline Migraine prophylaxis & 15 \\
\hline Migraine & 12 \\
\hline Convulsion & 5 \\
\hline Bipolar disorder & 4 \\
\hline Headache & 3 \\
\hline Neuralgia & 3 \\
\hline Convulsion prophylaxis & 2 \\
\hline Partial seizures & 2 \\
\hline Unknown & 11 \\
\hline \multicolumn{2}{|l|}{ Seriousness } \\
\hline Serious & 64 \\
\hline Nonserious & 32 \\
\hline \multicolumn{2}{|l|}{ Latency } \\
\hline$<7$ days & 8 \\
\hline I week to I month & 19 \\
\hline$>1$ month to 3 months & 14 \\
\hline$>3$ months to 6 months & 10 \\
\hline$>6$ months to I year & 3 \\
\hline$>1$ year to 5 years & 13 \\
\hline$>5$ years & 2 \\
\hline Not reported & 27 \\
\hline \multicolumn{2}{|l|}{ Reversibility } \\
\hline Reversible & 36 \\
\hline Not reversible & 20 \\
\hline Unknown & 40 \\
\hline
\end{tabular}

Note: ${ }^{\text {a Time course from the initial topiramate administration to the reported }}$ event of interest.

Abbreviation: VFD, visual field defect. and the TEAE, 9 cases reported a positive dechallenge, and 1 case reported a positive rechallenge. Based on the overall reporting rate in the Global Medical Safety worldwide safety database, VFDs occur at a rate of 1 per 118,339 person-years, and the assigned Council for International Organizations of Medical Sciences frequency category was "very rare."

\section{Case reporting positive rechallenge}

The patient experienced depression and visual scotoma 22 days after initiating topiramate therapy. Two months later, the dose was decreased from 50 to $25 \mathrm{mg}$ daily. Due to persistence of symptoms, therapy was withdrawn 2 months later. Approximately 1 month after stopping therapy, topiramate was restarted at $25 \mathrm{mg}$ daily and after some days, the patient again experienced the same symptoms.

\section{Marketing authorization holder comment}

The close temporal relationship between initiation of therapy and onset of the adverse event, continuation of the event during therapy, and the reappearance of symptoms when the patient was readministered topiramate suggest a relationship between the therapy and events. No ophthalmologic evaluation was provided to determine the nature and extent of the scotoma and to establish the similarity of the original event and that of the rechallenge.

\section{Discussion}

This comprehensive review examined the relationship between topiramate therapy and VFD ophthalmologic disorders by comparing its MOA in preclinical studies and available medical literature with other AEDs associated with VFD and assessed the sponsor's clinical database and postmarketing spontaneous reports for topiramaterelated VFDs.

The similarity in MOA of topiramate to other AEDs, for example, vigabatrin and pregabalin, which are associated with increased VFDs, suggested that VFDs may be a class effect. ${ }^{22,23}$ In particular, the GABA-ergic MOA of these AEDs is responsible for elevated GABA levels in the retina, which leads to retinal damage. However, it was found that other AEDs (eg, benzodiazepines, felbamate, levetiracetam, gabapentin, tiagabine, etc) with a GABAergic MOA are not associated with visual disorders, which suggests that VFDs are not a class effect for drugs with this MOA. ${ }^{17,18,22}$ The VFDs linked to vigabatrin therapy are related to dysfunction of GABA-ergic cells of the inner retina, which could be the primary target for toxic injury. ${ }^{24}$ Clinically, vigabatrin has been associated with permanent 
VFDs characterized by concentrically constricted fields. ${ }^{12,13}$ In contrast, topiramate has shown retinal protective properties in excitotoxin-induced neurotoxicity models. ${ }^{14}$ Topiramate has been associated with acute myopia which is associated with secondary angle-closure glaucoma, primarily due to drug-induced idiosyncratic ocular syndrome in reaction to the sulfamate moiety of topiramate, similar to that seen with other sulfa containing medications such as sulfamethizole, chlorthalidone, ethoxzolamide, hydrochlorothiazide, sulfapyridine, trimethoprim, and acetazolamide. ${ }^{25-27}$ Although this phenomenon is not completely understood, it is suggested that it could be caused by ciliary body swelling resulting in anterior movement of the lens, and by lens thickening. ${ }^{28}$

This review of the product sponsor's clinical trials database showed that while the drug exposure in OLTs was generally longer, the incidence of TEAEs suggestive of retinal dysfunction or damage with topiramate therapy in DBPCTs was similar to the OLTs for both approved and investigational indications. This suggests that increased dosing duration did not confer increased risk of VFDs. In addition, the VFDs in this study occurred following topiramate doses ranging from 50 to $1,000 \mathrm{mg} /$ day, which is similar to the reports in literature, suggesting that the severity of VFDs does not correlate with higher doses. ${ }^{29,30}$ In a case report, angle-closure glaucoma was reported in a patient with topiramate plasma levels that were lower than the therapeutic level. ${ }^{31}$ A limitation of this current review is that precise information of TEAEs and a dose-response relationship could not be determined. Thus, findings from the clinical trials in this study, and literature, suggest that the idiosyncrasy (unusual or odd behavior of person) hypothesis for topiramate-induced VFDs may be a possibility. Although the authors searched databases that included literature referencing, they did not conduct a formal literature review in the Embase and Medline search engines, and may thus have missed a limited number of additional reports.

For approved indications in children and adults, there was a higher incidence among epilepsy patients compared with migraine patients. For epilepsy patients, those treated with adjunctive topiramate had a higher incidence of VFD compared to monotherapy topiramate. However, the latter were also receiving concomitant AEDs, carbamazepine, valproate, gabapentin, and vigabatrin that are associated with visual disorders. ${ }^{22}$ It should also be considered that symptoms of aura can also occur in migraine or epilepsy. It is noteworthy that, compared to the general population, patients with epilepsy or migraine have a higher incidence of visual disturbances. In adult and pediatric patients with migraine treated with topiramate (Table 1), VFDs associated with topiramate therapy could be misdiagnosed as a migraine attack, and the patient could be treated with higher doses of topiramate, which could further aggravate the problem. ${ }^{32}$

In diabetic peripheral neuropathy DBPCTs, retinal hemorrhage was reported in a higher percentage of patients treated with placebo than in topiramate-treated patients. In the OLTs for investigational indications, all but one treatment-limiting adverse event was reported in patients from diabetic peripheral neuropathy studies, a population that is more prone to developing vision complications. This reiterates the fact that the underlying disease could be a potential confounder. Diabetic retinopathy is the leading cause of vision loss in adults of working age (20-65 years) in industrialized countries, and it is estimated that $>2.5$ million people worldwide are affected by it. ${ }^{10}$

In addition, the statistical analysis based on several DBPCTs (approved and investigational indications) comparing the occurrence of VFDs following topiramate and placebo treatment demonstrated that the RRs of VFDs were not significantly different for both. Few events were serious and treatment limiting, and most were reversible. Resolution of VFD symptoms upon discontinuation of topiramate has been reported in the literature. ${ }^{8,9,33,34}$

The review of cumulative postmarketing reports involving TEAEs of VFDs with topiramate treatment that was conducted for this current analysis showed that the majority of patients were adults (despite inclusion of both adults and children) and women. Although women have a marginally lower incidence of epilepsy than men, topiramate's other approved indication, migraine, occurs more frequently in women, with a ratio of 2.3:1 (women:men). ${ }^{35,36}$ In patients where latency was reported, three-fourths developed VFDs within 6 months of treatment initiation. A rechallenge in VFD was conducted to decipher the underlying mechanisms for TEAEs induced by the drug and was confirmed only in one patient. Thus, medically confirmed TEAEs of VFD that suggest a relationship between topiramate and VFDs as evaluated on the basis of temporal relationship, positive dechallenge or rechallenge, or presence of confounders were rare, and the majority were reversible.

One of the strengths of this study was that the results are based on a comprehensive and large database of patients, including randomized DBPCTs and long-term OLTs, in which safety during longer exposure periods was obtained. The occurrence of postmarketing reports of VFDs, including scotoma and maculopathy, was rare. Based on this comprehensive review of preclinical, clinical, and postmarketing 
information, ophthalmological TEAEs, including VFDs, do not appear to be a class effect for AEDs with similar GABAergic components in their MOA. A comprehensive review of topiramate data revealed a slightly increased incidence of visual TEAEs in topiramate-treated versus placebo-treated patients. However, RR assessment was found to be not significant, and thus clinical relevance of such risks cannot be ascribed to topiramate therapy. Warnings indicate that if any ophthalmologic event, symptom, or sign persists on examination during topiramate treatment, an evaluation by the prescribing physician would be required, which appears to be consistent with the level of risk identified in this study. Given topiramate's documented effectiveness for the approved therapeutic indications, ${ }^{19,37-39}$ the overall benefitrisk balance for its use, as indicated, remains favorable.

\section{Acknowledgments}

Dr Sangita P Patil and Dr Vaibhav R Deshpande (SIRO Clinpharm Pvt Ltd) provided writing assistance and Dr Wendy P Battisti (Janssen Research \& Development, LLC) provided additional editorial support and reviewed this manuscript. This study was funded by Janssen Research \& Development, LLC. The sponsor also provided a formal review of this manuscript.

\section{Disclosure}

Drs Ford, Selan, Greenberg, and Shi are employees of Janssen and hold company stocks. Dr Goldberg has received honoraria as a consultant from Janssen, Allergan, and Theravance. The authors report no other conflicts of interest in this work.

\section{References}

1. Topamax. Prescribing information [Internet]. Available from: https:// www.topamax.com/sites/default/files/topamax.pdf. Accessed July 12, 2016.

2. Shank RP, Gardocki JF, Streeter AJ, Maryanoff BE. An overview of the preclinical aspects of topiramate: pharmacology, pharmacokinetics, and mechanism of action. Epilepsia. 2000;41(Suppl 1):S3-S9.

3. Kuzniecky R, Ho S, Pan J, et al. Modulation of cerebral GABA by topiramate, lamotrigine, and gabapentin in healthy adults. Neurology. 2002;58(3):368-372.

4. Petroff OA, Rothman DL, Behar KL, Mattson RH. Human brain GABA levels rise after initiation of vigabatrin therapy but fail to rise further with increasing dose. Neurology. 1996;46(5):1459-1463.

5. Sills GJ, Butler E, Forrest G, Ratnaraj N, Patsalos PN, Brodie MJ. Vigabatrin, but not gabapentin or topiramate, produces concentrationrelated effects on enzymes and intermediates of the GABA shunt in rat brain and retina. Epilepsia. 2003;44(7):886-892.

6. Errante LD, Petroff OAC. Acute effects of gabapentin and pregabalin on rat forebrain cellular GABA, glutamate, and glutamine concentrations. Seizure. 2003;12(5):300-306.
7. Schiefer U. Visual field defects - essentials for neurologists. J Neurol. 2003;250(4):407-411.

8. Fraunfelder FW, Fraunfelder FT, Keates EU. Topiramate-associated acute, bilateral, secondary angle-closure glaucoma. Ophthalmology. 2004;111(1):109-111.

9. Mandal A, Chatterjee S, Bose S, Ganguly G. Ocular adverse effects of topiramate: two case reports. Indian J Pharmacol. 2008; 40(6): 278-280.

10. Quagliato LB, Barella K, Abreu Neto JM, Quagliato EM. Topiramateassociated acute, bilateral, angle-closure glaucoma: case report. Arq Bras Oftalmol. 2013;76(1):48-49.

11. Kjellström S, Bruun A, Isaksson B, Eriksson T, Andréasson S, Ponjavic V. Retinal function and histopathology in rabbits treated with topiramate. Doc Ophthalmol. 2006;113(3):179-186.

12. Kälviäinen R, Nousiainen I. Visual field defects with vigabatrin: epidemiology and therapeutic implications. CNS Drugs. 2001;15(3):217-230.

13. Wild JM, Martinez C, Reinshagen G, Harding GF. Characteristics of a unique visual field defect attributed to vigabatrin. Epilepsia. 1999; 40(12):1784-1794.

14. Yoneda S, Tanaka E, Goto W, Ota T, Hara H. Topiramate reduces excitotoxic and ischemic injury in the rat retina. Brain Res. 2003;967(1-2): 257-266.

15. Altman DG. Practical Statistics for Medical Research. Boca Raton, FL: Chapman \& Hall/CRC; 1991:611 p.

16. Nousiainen DI, Mäntyjärvi M, Kälviäinen R. Visual function in patients treated with the GABAergic anticonvulsant drug tiagabine. Clin Drug Investig. 2012;20(6):393-400.

17. Sills GJ, Patsalos PN, Butler E, Forrest G, Ratnaraj N, Brodie MJ. Visual field constriction: accumulation of vigabatrin but not tiagabine in the retina. Neurology. 2001;57(2):196-200.

18. Verrotti A, Lobefalo L, Priolo T, et al. Color vision in epileptic adolescents treated with valproate and carbamazepine. Seizure. 2004;13(6): 411-417.

19. Christensen J, Andreasen F, Poulsen JH, Dam M. Randomized, concentration-controlled trial of topiramate in refractory focal epilepsy. Neurology. 2003;61(9):1210-1218.

20. Arndt CF, Salle M, Derambure PH, Defoort-Dhellemmes S, Hache J-C. The effect on vision of associated treatments in patients taking vigabatrin: carbamazepine versus valproate. Epilepsia. 2002;43(8): 812-817.

21. Paulus W, Schwarz G, Steinhoff BJ. The effect of anti-epileptic drugs on visual perception in patients with epilepsy. Brain J Neurol. 1996; 119(Pt 2):539-549.

22. Verrotti A, Manco R, Matricardi S, Franzoni E, Chiarelli F. Antiepileptic drugs and visual function. Pediatr Neurol. 2007;36(6):353-360.

23. Zaccara G, Perucca P, Gangemi PF. The adverse event profile of pregabalin across different disorders: a meta-analysis. Eur J Clin Pharmacol. 2012;68(6):903-912.

24. Duboc A, Hanoteau N, Simonutti M, et al. Vigabatrin, the GABAtransaminase inhibitor, damages cone photoreceptors in rats. Ann Neurol. 2004;55(5):695-705.

25. Panday VA, Rhee DJ. Review of sulfonamide-induced acute myopia and acute bilateral angle-closure glaucoma. Compr Ophthalmol Update. 2007;8(5):271-276.

26. Thambi L, Kapcala LP, Chambers W, et al. Topiramate-associated secondary angle-closure glaucoma: a case series. Arch Ophthalmol. 2002;120(8):1108.

27. Tripathi RC, Tripathi BJ, Haggerty C. Drug-induced glaucomas: mechanism and management. Drug Saf. 2003;26(11):749-767.

28. Ikeda N, Ikeda T, Nagata M, Mimura O. Ciliochoroidal effusion syndrome induced by sulfa derivatives. Arch Ophthalmol. 2002;120(12): 1775.

29. Natesh S, Rajashekhara SK, Rao ASD, Shetty B. Topiramate-induced angle closure with acute myopia, macular striae. Oman J Ophthalmol. 2010;3(1):26-28. 
30. Tanaka S, Chuman Y, Akaike K, Doi W. [A case of topiramate-induced angle closure glaucoma]. Nihon Shinkei Seishin Yakurigaku Zasshi. 2011;31(3):131-133. Japanese.

31. Spaccapelo L, Leschiutta S, Aurea C, Ferrari A. Topiramate-associated acute glaucoma in a migraine patient receiving concomitant citalopram therapy: a case-report. Cases J. 2009;2(1):87.

32. Willett MC, Edward DP. Refractory topiramate-induced angle-closure glaucoma in a man: a case report. J Med Case Reports. 2011;5:33.

33. Asensio-Sánchez VM, Torreblanca-Agüera B, Martínez-Calvo S, Calvo MJ, Rodríguez R. [Severe ocular side effects with Topamax]. Arch Soc Esp Oftalmol. 2006;81(6):345-348. Spanish.

34. Foroozan R, Buono LM. Foggy visual field defect. Surv Ophthalmol. 2003;48(4):447-451.

35. Macgregor EA, Rosenberg JD, Kurth T. Sex-related differences in epidemiological and clinic-based headache studies. Headache. 2011; 51(6):843-859.
36. McHugh JC, Delanty N. Epidemiology and classification of epilepsy: gender comparisons. Int Rev Neurobiol. 2008;83:11-26.

37. Al Ajlouni S, Shorman A, Daoud AS. The efficacy and side effects of topiramate on refractory epilepsy in infants and young children: a multi-center clinical trial. Seizure. 2005;14(7):459-463.

38. Chung SS. A review of the efficacy and safety of extended-release topiramate in the adjunctive treatment for refractory partial-onset seizures. Ther Adv Neurol Disord. 2015;8(3):131-136.

39. Chung SS, Fakhoury TA, Hogan RE, et al. Once-daily USL255 as adjunctive treatment of partial-onset seizures: randomized phase III study. Epilepsia. 2014;55(7):1077-1087. 


\section{Supplementary material}

Table SI MedDRA (version 14.0) preferred terms suggestive of retinal dysfunction or damage

\begin{tabular}{|c|c|}
\hline Macular cyst & Macular ischemia \\
\hline Macular degeneration & Venous stasis retinopathy \\
\hline Age-related macular degeneration & Biopsy conjunctiva \\
\hline Macular opacity & Biopsy conjunctiva abnormal \\
\hline Maculopathy & Biopsy conjunctiva normal \\
\hline Vitreous adhesions & Biopsy cornea \\
\hline Pars plana cyst & Biopsy cornea abnormal \\
\hline Retinal cyst & Biopsy cornea normal \\
\hline Retinal degeneration & Biopsy retina \\
\hline Retinal depigmentation & Biopsy retina abnormal \\
\hline Retinal degeneration & Biopsy retina normal \\
\hline Retinal deposits & Biopsy sclera \\
\hline Retinal detachment & Biopsy sclera abnormal \\
\hline Retinal dystrophy & Biopsy sclera normal \\
\hline Retinal pallor & Fundoscopy \\
\hline Retinal pigment epitheliopathy & Fundoscopy abnormal \\
\hline Retinal pigmentation & Fundoscopy normal \\
\hline Retinal scar & Gonioscopy \\
\hline Retinal tear & Gonioscopy abnormal \\
\hline Retinopathy solar & Gonioscopy normal \\
\hline Retinoschisis congenital & Paracentesis eye \\
\hline Retinal toxicity & Paracentesis eye abnormal \\
\hline Macular hole & Paracentesis eye normal \\
\hline Osteoporosis-pseudoglioma syndrome & Retinogram \\
\hline $\begin{array}{l}\text { Detachment of retinal pigment } \\
\text { epithelium }\end{array}$ & Retinogram normal \\
\hline Retinal pigment epithelial tear & Retinogram abnormal \\
\hline Acquired pigmented retinopathy & Visual field tests \\
\hline $\begin{array}{l}\text { Laurence-Moon-Bardet-Biedl } \\
\text { syndrome }\end{array}$ & Visual field tests abnormal \\
\hline Macular pseudohole & Visual field tests normal \\
\hline Retinoschisis & Optic nerve disorder \\
\hline Subretinal fibrosis & Optic neuropathy \\
\hline Macular scar & Toxic optic neuropathy \\
\hline
\end{tabular}

(Continued)
Table SI (Continued)

\begin{tabular}{|c|c|}
\hline Retinal infiltrates & Visual pathway disorder \\
\hline Chorioretinitis & Visual evoked potentials \\
\hline Choroid tubercles & $\begin{array}{l}\text { Visual evoked potentials } \\
\text { abnormal }\end{array}$ \\
\hline Choroiditis & Visual evoked potentials normal \\
\hline Diabetic retinal edema & Blindness \\
\hline Macular edema & Chorioretinal atrophy \\
\hline Cystoid macular edema & Chorioretinal scar \\
\hline Retinal edema & Chorioretinopathy \\
\hline Retinal vasculitis & Choroidal detachment \\
\hline Retinitis & Choroidal effusion \\
\hline Retinitis viral & Choroidal hematoma \\
\hline Toxocariasis & Choroidal hemorrhage \\
\hline Vitreous abscess & Choroidal infarction \\
\hline Vitritis & Choroidal neovascularization \\
\hline Necrotizing retinitis & Choroidal sclerosis \\
\hline Hemianopia & Exudative retinopathy \\
\hline Hemianopia heteronymous & Optic atrophy \\
\hline Hemianopia homonymous & Optic disc disorder \\
\hline Scotoma & Optic disc drusen \\
\hline Tunnel vision & Optic nerve cupping \\
\hline Visual field defect & Papillophlebitis \\
\hline Uhthoff's phenomenon & Retinal artery embolism \\
\hline Macular vasospasm & Retinal artery occlusion \\
\hline Optic ischemic neuropathy & Retinal artery thrombosis \\
\hline Optic nerve infarction & Retinal disorder \\
\hline Retinal artery spasm & Retinal exudates \\
\hline Retinal artery stenosis & Retinal neovascularization \\
\hline Retinal ischemia & Retinal vascular disorder \\
\hline Retinal hemorrhage & Retinal vascular thrombosis \\
\hline Retinal vein thrombosis & Retinopathy \\
\hline Retinal vein occlusion & Venous stasis retinopathy \\
\hline Retinal vascular occlusion & Vitreous hemorrhage \\
\hline Retinal infarction & \\
\hline
\end{tabular}

Clinical Ophthalmology

\section{Publish your work in this journal}

Clinical Ophthalmology is an international, peer-reviewed journal covering all subspecialties within ophthalmology. Key topics include: Optometry; Visual science; Pharmacology and drug therapy in eye diseases; Basic Sciences; Primary and Secondary eye care; Patient Safety and Quality of Care Improvements. This journal is indexed on

\section{Dovepress}

PubMed Central and CAS, and is the official journal of The Society of Clinical Ophthalmology (SCO). The manuscript management system is completely online and includes a very quick and fair peer-review system, which is all easy to use. Visit http://www.dovepress.com/ testimonials.php to read real quotes from published authors. 